\title{
Trabajo libre y diversificación agrícola en Cuba: una alternativa a la plantación (1815-1840)
}

\author{
Consuelo Naranjo Orovio \\ y Mercedes Valero González. \\ Consejo Superior de Investigaciones Científicas, Madrid, \\ y Academia de Ciencias de Cuba
}

La entrada masiva de negros africanos y la creación de una economía de plantación y una sociedad esclavista en Cuba en el siglo XIX, no anularon la realización de otros proyectos que contenian el germen de una estructura social y económica diferente. Estos proyectos, muchos de ellos elaborados desde la Sociedad Económica de Amigos del País, se centraron en fomentar la población blanca, la creación de núcleos poblacionales y en diversificar y mecanizar la agricultura.

Junto al estudio de los proyectos de colonización blanca, analizamos algunas figuras destacadas de este pensamiento más liberal, que intentaron sacar a Cuba del monocultivo, como Alejandro Ramírez. José Cienfuegos, José María Calvo y Ramón de la Sagra.

En este estudio pretendemos demostrar cómo junto al trabajo esclavo, al crecimiento de la plantación y a la entrada masiva de negros africanos, existieron en Cuba otros proyectos económicos, que llevaban implícita una organización y estructura social diferente. Dichos proyectos fueron formulados por hacendados e intelectuales, muchos de ellos miembros de la Sociedad Económica de Amigos del País. '

Si bien en la elaboración de estos proyectos pesaban determinados factores como el "miedo al negro" y el temor a la "africanización" de la isla ante el paulatino $\mathrm{y}$, en determinados momentos, espectacular aumen-

I Alvarez Cuartero, Izaskun: "La Real Sociedad Económica de Amigos del País de La Habana y Ramón de la Sagra (1823-1832)", Ramón de la Sagra y Cuba, Vol.I, Sada-A Coruña, 1992, págs. 81-96; "Introducción al estudio de las Sociedades Económicas de Amigos del País en Cuba", Nuestra común historia. Cuba y España. Poblamiento y Nacionalidad. La Habana, 1993, págs. 79-86. La etapa de formación de la sociedad esclavista, de consolidación de una oligarquía, del nacimiento de instituciones culturales y del despertar de la ciencia ha sido estudiada en profundidad por $\mathbf{M}^{*}$ Dolores González-Ripoll Navarro en su tesis doctoral inédita titulada Ciencia, sociedad y cultura en la Cuba de finales del siglo XVIII: el gohierno de Luis de las Casas (1790-1796). 
to de la población de color, ${ }^{2}$ sin embargo creemos que los proyectos de colonización y diversificación agrícola se idearon como alternativa económica y social a la plantación. Aunque el "miedo al negro" existió, consideramos que su utilización por las autoridades y por algunos sectores de la oligarquía ha sido resaltada en exceso por las historiografías cubana y española.

Los primeros intentos por organizar, controlar y fomentar el territorio cubano se produjeron a finales del siglo XVIII, fundamentalmente con la expedición del conde de Mopox (1796-1802), durante la que se reconoció gran parte de la isla y se proyectó la creación de diferentes núcleos urbanos, muchos de ellos en lugares costeros, a partir del establecimiento de poblaciones que obedecían a criterios estratégicos y económicos: inicio de nuevos cultivos, explotación de tierras baldías y conexión de unas poblaciones con otras que permitirían la creación de redes de mercado interno. ${ }^{3}$ Algunos de estos proyectos fueron hechos realidad en el siglo XIX al establecerse una política poblacionista, dirigida desde la Sociedad Económica y que tenía como fin fomentar la población y la colonización blanca en Cuba. Con este objetivo se constituyó, dentro de la Sociedad Económica, la Comisión de Población Blanca en 1812, que a partir de 1818 pasó a denominarse Junta de Población Blanca.

El reconocimiento y examen de los recursos naturales, estado de la agricultura, naturaleza y número de los habitantes de la isla realizado en los primeros meses de 1816, demostraron una vez más el estado de "abandono" del país en términos de indefensión, despoblación y precariedad de los campos. Como en otros memoriales, el fomento de la población era el factor fundamental para lograr el crecimiento económico deseado y la defensa del territorio. La explotación de los recursos agrícolas, y no

2 La introducción masiva de negros africanos produjo un aumento demográfico y un desequilibrio en la población entre las étnias de la isla. El informe de Antonio del Valle Hernández de 1811 evidencia el ascenso progresivo de la población de color, sobre todo en la jurisdicción de La Habana. La desproporción entre los tres grupos - población blanca que representaba el $45 \quad 1 / 2$, el grupo compuesto por los libres de color con un 19, y los esclavos que representaban el 35 1/2 en toda la isla- fue aumentando de forma gradual en los años siguientes. En 1827 la población blanca representaba el $44 \%$ del total de la población. Esta estructura demográfica comenzó a variar a partir de 1837 como consecuencia de la disminución relativa de la población negra. Véase Consuelo Naranjo Orovio: "Medio siglo de política poblacionista en Cuba, 1790-1840", IX Congreso Internacional de Historia de América. Vol. 1, Sevilla, 1992, págs. 321-339.

3 Naranjo Orovio, Consuelo: "Fomento y reorganización del territorio: un proyecto perdurable del Conde de Mopox y Jaruco", Cuba ilustrada. La Real Comisión de Guantánamo, 17961802. T. I, Madrid, 1992, págs. 53-75. 
sólo el cultivo de cañaverales, permitiría obtener una mayor oferta de productos y cultivar "mejores frutos deseados por las demás naciones".

Con este espíritu, presente en la política poblacionista auspiciada y desarrollada desde la Junta de Población Blanca, en 1817 se adoptó la Real Cédula de Población del 21 de octubre, otorgada para Puerto Rico en 1815. ${ }^{4}$ Con la aplicación en Cuba de esta real cédula quedaban derogadas todas las leyes y disposiciones legales que limitaban la entrada de inmigrantes y extranjeros a la isla y se abría una nueva vía que facilitaba la entrada de familias españolas y, a falta de éstas, extranjeras de países amigos, que cumplieran los requisitos establecidos en la real cédula. Las condiciones establecidas hacían referencia al color, religión y ocupación laboral. Los colonos deberían ser blancos, desempeñar oficios productivos como albañil, tonelero, labrador, carpintero, picapedrero, etc. y católicos, condición, está última, sin la cual los extranjeros no podrían domiciliarse. Tras su llegada a la isla, para su domiciliación, el colono quedaba registrado en un libro de matrículas en el que se hacía constar su patria, oficio, partido en donde se fuera a establecer y caudal o bienes que manifestara poseer.

Asimismo, los extranjeros católicos deberían domiciliarse y jurar fidelidad y vasallaje al rey. Su condición de extranjeros les restringió, al menos durante los cinco primeros años de su asentamiento, algunos de los derechos otorgados a los colonos españoles. Así, mediante el artículo 18 de la real cédula, les quedaban prohibidos la posesión de una tienda, almacén o embarcación y el ejercicio del comercio marítimo, a excepción de las sociedades o contratas, verbales o escritas, hechas con españoles. Pasados estos cinco primeros años, en el caso de querer naturalizarse deberían prestar un "juramento de naturalización", mediante el cual prometerían fidelidad a la religión católica, al rey y a las leyes, a la vez que renunciarían a todo fuero, privilegio o protección de extranjería. Una vez naturalizados, tanto a ellos como a sus hijos y descendientes, se les concederían todos los derechos y privilegios, como a cualquier vecino español de la isla: protección del gobierno, derecho a comprar propiedades, a cambiar la residencia en el territorio insular, a disponer de sus bienes por testamento, en caso de fallecimiento, así como a establecer industrias en cualquier partido de la isla.

4 Archivo Nacional de Cuba, La Habana (en adelante, ANC). Real Consulado y Junta de Fomento, Leg.185, núm. 8357. 
Los colonos estaban tibres de todo tributo personal, a excepción del que debían satisfacer por sus esclavos negros o pardos, a razón de 1 peso anual, después de los diez primeros años de su establecimiento en Cuba. En aquellos casos que durante los cinco primeros años el colono quisiera volver a su lugar de origen o marchar a otro país, éste podría llevarse los bienes que en su momento trajera consigo, debiendo de pagar un $10 \%$ sólo por aquellos bienes o ganancias que hubiera obtenido durante su estancia en Cuba. Los artículos 8 y 9 de la Real Cédula contienen los demás privilegios de los que gozarían los colonos, quienes estarían exentos de pagar el diezmo y la alcabala de los frutos producidos durante quince años, transcurridos los cuales sólo pagarían un cuarto del diezmo y de la alcabala. La exención total del pago de alcabala se extendía a todos los productos cuyo transporte y comercio se realizase por barcos españoles y con territorios españoles.

A cambio de estos privilegios los colonos tenían la obligación de defender la isla ante cualquier ataque del exterior o revuelta interna causada por los esclavos. Sin llegar a constituir una milicia reglada, se pretendía que los colonos tuviesen armas para cualquier emergencia, que deberían presentar cada dos meses al gobernador u oficial destinado a realizar la revista.

La falta en la real cédula de algún artículo que hiciera referencia a las tierras que debían repartirse entre los colonos fue suplida antes de su aprobación por las autoridades. Aunque se propuso el nombramiento de tres vecinos respetables, que se encargarían de supervisar los proyectos, se recomendaba que se mantuviera a José Ricardo O'Farril, Juan Montalvo y Andrés de Jaúregui, que integraron la Comisión desde su nacimiento. Asimismo se aconsejaba como medios más efectivos para llevarla a cabo y para conseguir el establecimiento definitivo del colono en la isla el reparto de tierras realengas, fundamentalmente de la parte oriental, por ser el lugar donde existían un mayor número de realengos y en el que era "más urgente aumentar la población de blancos honrados", así como que los parajes elegidos para su asentamiento contaran con población femenina con el fin de facilitar matrimonio a los colonos. ${ }^{5}$

Los planes de colonización diseñados en esta época contaron con el apoyo del intendente de Hacienda Alejandro Ramírez y del entonces capitán general, José Cienfuegos. La concepción que de Cuba y su futuro

5 Biblioteca Nacional José Martí, La Habana. CM Sociedad Tomo 61, núm. 1. 
tenían ambos, hace que sean claves en la política de colonización blanca. Ellos proyectaron crear las bases económicas que posibilitaran a Cuba autoabastecerse, crear una "Cuba pequeña", como ellos la denominaban, alejada del latifundio y la plantación, que permitiera el cultivo de productos menores, que a su vez potenciarían el comercio interno y externo. Una forma de salir del monocultivo azucarero que encerraría, como así fue, a Cuba en sí misma. Esta transformación económica llevaba consigo una transformación social ya que serían pequeños campesinos los encargados de cultivar las tierras. La creación de este pequeño campesinado, propietario y blanco, constituiría la base de la futura sociedad cubana.

Las familias y colonos llegados a la isla se instalarían o bien en terrenos de los hacendados que los hubieran solicitado, o bien en terrenos cedidos o vendidos a la Junta. Con la instalación de estas familias también se perseguía otro objetivo: poblar los territorios despoblados mediante la creación de colonias agrícolas, núcleos urbanos cuyo diseño correspondía al trazado en las Ordenanzas de Nuevas Poblaciones dadas en el siglo XVII. Para llevar a cabo sus planes contaron con la ayuda de algunos hacendados e intelectuales que desde la Sociedad Económica de Amigos del País y la Junta de Fomento trabajaron por llevar a Cuba los nuevos avances científicos y tecnológicos, cuya aplicación a la agricultura reportaría un mayor crecimiento económico al país. Crecimiento que para ellos no residía tan sólo en el avance del latifundio y en el aumento de las dotaciones de esclavos, sino en la llegada de colonos, de familias blancas, que se emplearían en el cultivo de la tierra, como propietarios o arrendatarios, para producir otros cultivos como maíz, algodón, trigo, arroz, añil, naranjas, etc., o para criar ganado mayor y menor. Estos hacendados fueron, en el sentir de Ramiro Guerra, quienes “ ... lucharon para que su país no fuera un taller donde tan sólo se cultivaran y elaboraran materias tropicales a manos de razas distintas de la blanca, o simple factoría de comercio y navegación. ... (ellos) lograron que el padre Varela y Saco, para responder a las exigencias de la industria azucarera, iniciasen en Cuba la enseñanza de la física y la química; ... los que además de gestionar y patrocinar todas las reformas de carácter económico, social y político introducidas en Cuba en las primeras décadas del siglo XIX, abogaron enérgicamente por la inmigración y colonización blanca". ${ }^{6}$

6 Guerra, Ramiro: Azúcar y población en las Antillas. La Habana, 1970, pág. 56. 


\section{Nuevas poblaciones: San Fernando de Nuevitas y Fernandina de Jagua}

La ejecución de la real cédula de 1817 dio pronto resultados efectivos. Desde esa fecha y hasta 1820 entraron en la isla más de 10.000 colonos, de los cuales 5.000 fueron destinados a las poblaciones de Jagua y de San Fernando de Nuevitas, para cuya instalación y socorro se contó con los fondos procedentes del arbitrio de 6 pesos creado sobre cada negro varón esclavo introducido. El dinero recaudado fue destinado al mantenimiento de los colonos indigentes durante los primeros meses, a razón de 22 pesos con 4 reales por persona, y, los restantes 20.000 pesos, a la compra de la hacienda de Santo Domingo, de 4 leguas de extensión, situada diez leguas al oeste de Santa Clara.

Con el fin de obtener recursos para facilitar y encauzar la colonización la Comisión, reunida en febrero de 1818, acordó dirigir una circular a los hacendados de la isla, en la que se les solicitaba apoyo en sus gestiones y ayuda económica. En dicha circular, firmada por José Cienfuegos y Alejandro Ramírez, se requería que los hacendados se encargasen del alojamiento y mantenimiento de los colonos en sus casas o en pueblos cercanos, al menos por dos meses, hasta que el gobierno encontrase el paraje y las condiciones para su instalación. Al frente de la organización seguían permaneciendo José Ricardo O'Farril, Andrés de Jaúregui y Juan Montalvo, a quienes deberían de dirigirse aquellos hacendados que quisieran colaborar con el gobierno, indicando el número de familias o de colonos que estaban dispuestos a albergar y la preferencia, si la hubiera, de que fueran españoles o extranjeros católicos. ${ }^{7}$

En el período que aquí analizamos se sucedieron diferentes proyectos de colonización, algunos de los cuales dieron como resultado la creación de núcleos urbanos. La parte oriental del país era una de las zonas que desde años anteriores demandaba con más urgencia la puesta en marcha de proyectos de colonización; necesidad que fue recogida en la real cédula de 1817 y atendida por los miembros de la Comisión y del gobierno, quienes acordaron nombrar un comisionado, en la persona de Joaquín Bernardo Campuzano, regente de la Real Audiencia de Puerto Príncipe, para llevar a cabo sus proyectos. El establecimiento de los po-

7 Memoria de la Sociedad Económica de Amigos del País, núm. 16, La Habana, 30 de abril de 1818 . 
bladores en la costa, en Nuevitas, y en el interior se haría de acuerdo a lo estipulado en la Real Cédula de 1817. Su posición estratégica haría de la nueva población de San Fernando de Nuevitas un puerto de gran valor que posibilitaría la entrada y distribución a Puerto Príncipe de mercancías. Por ello, se preveía que una vez establecida la aduana, aunque fuera provisional, se le dotaría de todos los privilegios de puerto menor que gozaban Matanzas, Trinidad y Cuba. Delimitado el lugar donde se instalarían los colonos, el comisionado mandaría levantar un plano formal conforme a las reglas de salubridad, policía y ornamento, en el que también figurasen los edificios públicos y privados. ${ }^{8}$

La otra colonia fundada fue Fernandina de Jagua, actual Cienfuegos, creada a partir de la propuesta que Luis de Clouet elevó a Alejandro Ramírez y José Cienfuegos, en 1819, para establecer una población en la bahía de Jagua a base de colonos blancos católicos y españoles o naturalizados españoles. ${ }^{9}$ En el proyecto presentado por Clouet se recomendaba la compra de cien caballerías de tierra en los terrenos del hato Caunao, propiedad de particulares en ese momento, para su distribución gratuita entre las cuarenta familias de agricultores instaladas en la colonia a lo largo de los dos primeros años de su fundación, con la previsión de una posible adquisición adicional de otras cien caballerías. Por cada colono blanco mayor de 18 años se concedería una caballería de tierra con las condiciones de iniciar su desmonte y cultivo en los seis primeros meses y haber logrado un rendimiento efectivo de al menos la mitad de la tierra en los siguientes dos años. Pasados los dos primeros años de la fundación, las tierras se venderían a censo redimible a razón el primer año de 100 pesos caballería; el segundo año a 125 pesos, el tercero a 150 pesos, el cuarto a 200 pesos y así sucesivamente, hasta 1830 en que se estudiarían las nuevas condiciones.

A partir del cuarto año de la posesión de las tierras debía pagarse un rédito de un $5 \%$ anual, entendiéndose que todas estas medidas afectaban sólo a las tierras repartidas por el gobierno. Las tierras podrían ser vendidas a partir del quinto año, fecha en la que pasaban a ser propiedad de los colonos, siempre que éstos permanecieran en Cuba.

La contrata establecía que los alimentos, útiles de labranza e instrumentales de industria, así como los negros bozales, estarían libres de im-

8 Ibídem. La Habana, 1818, págs. 117-121.

9 Naranjo, Consuelo, y Puig-Samper, Miguel Angel: "Colonos franceses en el poblamiento de Cienfuegos", Emigración francesa a América. Bordeaux (en prensa). 
puestos durante los primeros cinco años. Las manufacturas de distintos tejidos, algodón, lino, etc., y mercancías de comercio pagarían la mitad de lo establecido para otros puertos, durante el mismo tiempo.

El transporte e instalación de las familias a la colonia Fernandina de Jagua correrían a cargo del promotor. Por ello el gobierno le concedería, durante los dos primeros años, del fondo de población 30 pesos fuertes por persona mayor de 15 años y 15 pesos fuertes por cada menor de 15 años, siempre que procediesen de La Luisiana o de cualquier otro punto del norte de América. Estas cuotas se doblaban en el caso de los colonos procedentes de Europa. Asimismo, durante los seis primeros meses el gobierno pagaría a Clouet 3.5 reales diarios por adulto y la mitad por cada menor de 10 años. Dicho dinero sería administrado por Clouet, quien debía encargarse del suministro de las raciones. Entre las funciones de Clouet también se encontraban el actuar como juez inmediato y medianero para resolver las desavenencias entre los colonos. También se preveía el nombramiento de un sacerdote, un médico y un agrimensor, elegidos y pagados por el gobierno.

Una vez instaladas las primeras cuarenta familias, se consideraría a don Luis de Clouet fundador de la nueva población, de acuerdo a las Leyes de Indias. La fundación de la colonia se dio por realizada en abril de 1819 , una vez instalados los primeros pobladores.

Los primeros colonos llegados desde Burdeos en 1819 procedían de diferentes partes de Europa - Francia, España, Alemania e Italia- y de Guarico. El total de colonos forasteros y extranjeros mayores de 18 años era de 459 , y menores de 18 años 122 colonos. El número de pobladores naturales de la isla era 197, mayores de 18 años, y 222 pobladores menores de esa edad. La distribución total de las tierras y solares terminó en 1825. La colonia, que contaba con una extensión de 272.122 caballerías y cordeles, se organizó en cuatro barrios: Cienfuegos, Clouet, Cagigal y Ramírez.

Los planos de la ciudad, levantados por Félix Bouyon y Alejo Helvecio Lanier, en 1836 y 1839 respectivamente, siguen las normas para la creación de poblaciones recogidas en las Nuevas Ordenanzas, integradas en la Recopilación de las Leyes de Indias de 1681.

A partir de estos dos planos y de lo dispuesto por el gobierno superior sobre el reparto y localización de los edificios y casas principales, reconstruiremos el tejido urbano y la disposición de las casas y sus propietarios. Alrededor de la Plaza Mayor o Plaza Real se edificarían los edificios del gobierno y los públicos, la casa del cura y la iglesia. De la 
Plaza Real rectangular salían cinco calles, trazadas a "regla y cordel", que llevaban por nombre San Fernando, San Luis, Santa Isabel, San Carlos y Bouyon. Asimismo se proyectó la creación de otra plaza (Plaza de la Aduana) fuera del núcleo urbano - junto a los muelles- y dos paseos - Paseo de Arango y Paseo de Vives- que cerrarían la ciudad, en una cuadrícula perfecta por sus lados este y oeste.

En la parte norte de la ciudad se levantarían los edificios destinados al cuartel, al hospital y al consejo. Ya fuera del núcleo urbano, en el ejido, se localizaba el cementerio.

En el plano de Lanier se proyecta de cara al futuro y como ampliación del núcleo urbano otra plaza, también rectangular y atravesada por dos paseos. En cuanto a la construcción de las casas de los colonos, en el término de seis meses, contados desde el primer día de la posesión, éstos estaban obligados a levantar sus casas en los solares a ellos donados de forma gratuita.

En los años 1821 y 1822 continuó la entrada de colonos, tal como refleja el padrón del 20 de diciembre de 1822 , que señala un total de 2.252 habitantes. En él se observa un incremento del número de esclavos introducidos y el aumento de la población joven, masculina y femenina. Los problemas surgidos en la colonia a raíz del deslinde de las tierras y de la competencia entre diferentes jurisdicciones provocaron el envío casi continuo, a lo largo de la década de los 20 , de funcionarios que informasen al gobierno sobre el estado y los progresos de la colonia. Finalmente, los informes positivos sobre la colonia y su fundador, de finales de 1826, dieron como resultado la aprobación, en 1829, de parte de las solicitudes que en 1823 Luis de Clouet había elevado a las autoridades. Entre éstas hay que destacar la otorgación a Clouet del gobierno político y militar de la colonia, que podría dejar en la persona de Alejandro Clouet o el oficial que eligiera, el nombramiento de un asesor teniente de gobernador letrado para la administración de la justicia, la concesión del título de Villa para el pueblo de Cienfuegos, capital de la colonia, el 20 de mayo de 1829, y la autorización de traer de las islas Canarias familias para establecerse en Fernandina.

Los datos que poseemos sobre el estado de Fernandina de Jagua en los años 30 no son muy halagüeños. La actividad económica y comercial seguía siendo lenta por su ubicación en la costa sur y por carecer de buenas comunicaciones. La única curiosidad de la colonia, que la hace diferente a otras poblaciones, es el número de trabajadores blancos en 
ingenios, cafetales, potreros y sitios de labor, superior al de los existentes en otras jurisdicciones y que, en 1838, tenían una proporción aproximada de 1 trabajador blanco por cada 3 esclavos: 1.322 empleados blancos por 4.209 esclavos.

Para estos años la villa de Cienfuegos, a cuyo frente se encontraba el brigadier Carlos Tolra, ya contaba con algunos de los edificios públicos principales. En 1839 se terminaron de edificar la Plaza de Armas, un teatro, una escuela gratuita y el cementerio general, a la vez que se presentaron proyectos para construcción de muelles y para dotar a la villa de alumbrado público. Además se había realizado un reconocimiento para la conducción de agua del arroyo que nacía en el ingenio de Santa Cruz, por el ingeniero Alejo $\mathrm{H}$. Lanier, quien en 1842 presentó un interesante proyecto para la construcción del tendido ferroviario entre Cienfuegos y Villa Clara. En 1842 la Junta de Población Blanca retiró a Fernandina de Jagua los privilegios, al considerar que la fundación ya estaba finalizada y sus habitantes estaban produciendo. Con más de 20.000 habitantes, la colonia había conseguido una estabilidad y progreso que la situaba entre una de las poblaciones más adelantadas del país.

\section{Pequeño campesinado y diversificación agrícola}

Todos estos proyectos de colonización cobran mayor entidad si ponemos en relación la entrada de colonos y el fomento de otros cultivos, o, si se quiere, los proyectos ideados para la diversificación agrícola. Dichos proyectos, a su vez, están íntimamente relacionados con los adelantos científicos e innovaciones tecnológicas que se fueron aplicando a la agricultura cubana. Fueron los mismos hacendados que abogaban por la introducción de colonos o trabajadores libres, los que también apoyaron la diversificación agrícola y el cultivo de otros productos, precisamente a manos de pequeños campesinos libres, propietarios o arrendatarios.

Uno de los mejores ejemplos de los intentos de la Sociedad por diversificar y tecnificar la agricultura cubana lo constituye la agricultura cerealera. Estos proyectos comenzaron en 1819 en Güines (arroz) y Villa Clara (trigo). ${ }^{10}$ La puesta en marcha de estos cultivos permitiría no

10 Los estudios sobre diversificación agrícola realizados en Cuba a lo largo del siglo XIX, y fundamentalmente los relacionados con el cultivo del trigo, han sido analizados de forma exhaustiva por Rolando Misas: Diversificación y tecnificación agrícola en la Sociedad Económica de Amigos del País de La Habana (1793-1866), en prensa. 
sólo realizar su objetivo central, la diversificación y tecnificación agrícola, sino también, como ya comentamos, el poblamiento a base de colonos blancos de zonas despobladas y la creación de un mercado interno.

Para la realización de sus proyectos en estos años los hacendados contaron con una figura cuya obra y pensamiento fue esencial, nos referimos a Ramón de la Sagra. En sus obras siempre estuvo presente la lucha contra el monocultivo, al que consideraba un factor de atraso y limitación de un pueblo y de su agricultura. Frente al monocultivo, la Sagra resaltaba los beneficios económicos y sociales de una agricultura diversificada que provocaría el establecimiento de industrias rurales y de manufacturas. "Para llevar a cabo sus proyectos y los presentados en la Sociedad Económica por otros intelectuales, la Sagra establecía como primera necesidad la transformación técnica en la agricultura; transformación que sólo era posible realizar mediante el cambio del sistema de trabajo, del esclavo al libre. La imposibilidad del esclavo de realizar un trabajo que no fuera meramente manual se debía, para la Sagra, a su condición de esclavo y no por su pertenencia a una etnia determinada. Para él los negros se encontraban en un estado de "apatía salvaje", que guarda relación directa con el medio físico donde vivían antes de ser esclavizados. Dicho estado fue reforzado por la esclavitud "un sistema, carente de estímulo y que - en opinión de la Sagra - elimina completamente la inteligencia del operario, para que predomine exclusivamente su fuerza muscular". En sus escritos se repiten los argumentos en contra de la esclavitud, no sólo por el carácter inhumano del sistema, sino por ser, desde un punto de vista económico, el factor que impedía la organización de un sistema agrícola y de economía rural fundada en principios científicos, y que limitó a la agricultura de las Antillas a un número pequeño de cultivos, como el café y el azúcar. En estas condiciones, el esclavo era incapaz de incorporar en su trabajo ningún tipo de máquina, utensilio o adelanto tecnológico, dejando a la agricultura en el estado en que se encontraba, con la fuerza física como único elemento para su cultivo, la rutina como única ley agrícola y la abundancia de los productos como exclusivo resultado de la administración económica.

En el análisis que Ramón de la Sagra realizaba sobre las causas del atraso de la producción cubana, en 1845, planteaba como solución para

11 Sagra, Ramón de la: Cuba:1860. Selección de artículos sobre agricultura cubana. La Habana, 1963. 
desarrollar el cultivo la incorporación del trabajador libre, ya que la transformación tecnológica de la industria azucarera sólo podía ser viable mediante la separación del trabajo agrícola del sector fabril, y la introducción de trabajadores libres. Para él la única solución era la introducción de inmigrantes asiáticos y de colonos blancos, que en la industria azucarera trabajasen sembrando caña en tierras dadas a censo reservativo o arrendadas, o bien trabajasen en el cultivo de otros productos necesarios en la industria europea. Sus argumentos en este sentido se repiten constantemente a lo largo de su obra:

"El cultivo por medio de brazos blancos, ..., es el ancla firme de salvación que tienen las Antillas españolas y de que más o menos carecen las extranjeras". 12

Para apoyar sus ideas la Sagra de nuevo pone su mirada en Europa y comenta los proyectos de colonización blanca que en los mismos años estaban gestionando Francia y Gran Bretaña en sus posesiones antillanas, para proponer, finalmente, en 1845, la creación de una empresa de colonización.

\section{Mecanización y diversificación agrícola en el proyecto de Ramón de la Sagra}

La Sociedad Económica de La Habana, como representante de la política reformista del ilustrado gobierno español, se dedicó, entre otros proyectos, a conformar un programa de desarrollo agrícola orientado a reorganizar la agricultura cubana, a fin de superar el estado de atraso en que se hallaba como consecuencia del monocultivo, dotarla de una adecuada tecnología y sustituir la mano de obra esclava por trabajadores libres. Los esfuerzos realizados están contenidos en los proyectos presentados en esta corporación por algunos hacendados con una mentalidad más abierta y receptiva, algunos de ellos intelectuales, partidarios de la creación de cátedras de botánica y escuelas de agricultura práctica, en las que se impartiera una enseñanza que conjugara los conocimientos tradicionales con la asimilación de las experiencias alcanzadas en los países europeos. ${ }^{13}$

12 Ibidem, pág. 216.

13 Misas Jiménez, Rolando: "La Real Sociedad Patriótica y las investigaciones aplicadas a la agricultura", Cuba, la Perla de las Antillas. Madrid-Aranjuez, (en prensa). 
En este sentido, caben señalar las propuestas de Juan Manuel O'Farrill y Nicolás Calvo de la Puerta, quienes en 1793 abogaron por la utilidad de la botánica para el desarrollo agrícola del país y por la conveniencia de fundar escuelas que promovieran, entre otros aspectos, la introducción de nuevos cultivos. ${ }^{14}$ Fomentar una agricultura diversificada con una base tecnológica apropiada era uno de las principales aspiraciones de algunos miembros de la Sociedad Patriótica, que respondían a una mentalidad más liberal y que, en cierto modo, preveían las dificultades que el monocultivo conllevaría para el desarrollo de la isla. Sin lugar a dudas, estos proyectos suponían cambios en el orden económicosocial, algunos de los cuales entraban en contradicción con los intereses de los poderosos hacendados criollos y comerciantes peninsulares, preocupados por mantener su status económico y social, derivado del sistema agrícola establecido y la esclavitud. ${ }^{15}$

Dentro de esta corriente de pensamiento hay que destacar la figura del hacendado José María Calvo, que en 1818 propuso la creación de una escuela de agricultura práctica, fundamentando en su Cartilla rústica el criterio de organizar cursos gratuitos para el cultivo y ensayo de plantas útiles, así como estimular a los agricultores a introducir nuevos cultivos y maquinaria agrícola mediante la convocatoria de premios. ${ }^{16}$

Como las anteriores propuestas, este proyecto tampoco recibió el apoyo necesario a pesar de que ya hacía un año que se había creado el Jardín Botánico de La Habana y se hacían esfuerzos por organizar en el mismo una cátedra de botánica, concebida más por su utilidad médica que por la aplicación de una enseñanza agrícola. ${ }^{17} \mathrm{De}$ este modo, el interés de la Real Sociedad Patriótica y en particular del intendente Alejandro Ramírez no coincidía con los proyectos puestos en marcha por el director del Jardín habanero, José Antonio de la Ossa, quien prestó mayor atención a la organización y clasificación de las plantas que a la in-

14 Calvo, Nicolás: "Discurso de Nicolás Calvo promoviendo el establecimiento de una escuela de Química y Botánica", Memorias de la Sociedad Patriótica de La Habana, La Habana, 1793, T. I, pág. 155.

15 Moreno Fraginals, Manuel: El ingenio. 2 tomos. La Habana, 1978. Cepero Bonilla, Raúl: Azúcar y abolición. Barcelona, 1977.

16 Bachiller y Morales, Antonio: Apuntes para la historia de las letras y de la instrucción pública en la Isla de Cuba, La Habana, 1859, T. I, pág. 113.

17 Valero, Mercedes: "El Jardín Botánico de La Habana en el siglo XIX", Anuario, núm. 1, La Habana, 1988, págs. 248-271. Puig-Samper Mulero, Miguel Angel: "Las primeras instituciones científicas en Cuba: el Jardín Botánico de La Habana", Cuba, la Perla de las Antillas. Madrid-Aranjuez (en prensa). 
troducción de estudios agrotécnicos. Los partidarios de institucionalizar la enseñanza de la agricultura mostraban entusiasmo por estos proyectos, sobre todo los pequeños hacendados, que veían en estas medidas la posibilidad de superar la crítica situación económica.

El anhelo de reformar la agricultura en Cuba tuvo también como representante a Ramón de la Sagra, quien a su llegada a la Isla en 1823 y preocupado por la difícil situación económica de Cuba, comenzó a analizar los factores responsables del atraso. ${ }^{18} \mathrm{El}$ monocultivo, la condición monoexportadora y la creciente importación de bienes de consumo fueron objeto de profundas reflexiones que le permitieron valorar la dependencia de la agricultura en relación con el mercado extranjero, así como otros aspectos que obstaculizaban el crecimiento económico de Cuba; por ejemplo, la política arancelaria, la falta de interés por los avances científicos y el empleo de una fuerza de trabajo totalmente improductiva como el esclavo; sin embargo, las favorables condiciones naturales de la Isla estimularon a Sagra a la búsqueda de soluciones, priorizando la agricultura cubana a través de un ambicioso proyecto. ${ }^{19}$

El programa agrícola propuesto por Ramón de la Sagra pretendía establecer una industria rural diversificada, basada en la introducción de nuevos cultivos y la asimilación de procedimientos tecnológicos que se aplicaban en otros países con excelentes resultados; sin embargo, la incorporación de técnicas novedosas al trabajo agrícola y fabril, que sugería separar, exigía una mano de obra capaz de abordar trabajos más complejos. Por ello Sagra dedicó atención al análisis de la improductividad del trabajo del esclavo planteando como alternativa, dentro de su proyecto, la introducción de mano de obra asalariada.

Sagra era partidario de los proyectos de colonización blanca que se venían fomentando en la Isla y de la transformación de las grandes haciendas en pequeñas propiedades agrarias, donde se ensayarían nuevos cultivos con técnicas avanzadas, que proporcionarían una mayor producción y, por ende, la variabilidad de productos agrícolas para la alimentación y aplicación industrial. En sus planteamientos la pequeña propiedad era la vía idónea para desarrollar un sistema más productivo y rentable, frente al establecido en las grandes haciendas azucareras y cafetaleras.

18 Puig-Samper Mulero, Miguel Angel: "Ramón de la Sagra, director del Jardín Botánico de La Habana", Ramón de la Sagra y Cuba. Vol. 1, Sada-A Coruña, 1992, págs. 61-80.

19 Sagra, Ramón de la: Historia física, política y natural de la Isla de Cuba (Introducción), T. I. París, 1845, pág. 25. 
Con vistas a materializar estas ideas, Ramón de la Sagra propuso establecer una escuela especial de agricultura, a modo de ensayo que pretendía extender a toda la Isla. La creación de este tipo nuevo de escuela coincidiría con los proyectos de enseñanza agrícola presentados en la Sociedad Patriótica y comentados anteriormente. Estas ideas de Sagra sólo contaron, como es lógico, con la atención de aquel sector que dentro de esta corporación promovía criterios cercanos al pensamiento científico europeo.

Los primeros pasos dados por Ramón de la Sagra para fomentar la institucionalización de la enseñanza agrícola, tuvo como escenario la cátedra de botánica agrícola del Jardín Botánico, fundada en 1824, de la que fue titular. Allí desarrolló una interesante actividad docente combinando el ensayo de nuevos cultivos, la formación de herbarios y la organización científica del jardín. ${ }^{20}$ A pesar de sus esfuerzos, las condiciones de esta institución no permitieron llevar a cabo todas sus aspiraciones, en especial la de crear una "hacienda modelo" al estilo de las que existían en Europa.

La experimentación de algunos cultivos, algunos de ellos ya introducidos en el Jardín Botánico, como el añil, el cacao, el trigo y el maiz, entre otros, así como el conocimiento de los progresos de la ciencia en otros países como Francia, Inglaterra y Estados Unidos, le sirvieron de base para presentar a las autoridades, en 1827, una memoria en la que sugería una serie de medidas orientadas a reorganizar la agricultura. Entre estas medidas hay que destacar la relacionada con la creación de una escuela práctica donde se combinara la actividad docente y la investigación.

Para Ramón de la Sagra esta escuela significaba la oportunidad de introducir técnicas modernas de cultivo, instrumentos agrícolas más eficientes y la posibilidad de formar un personal capacitado para desarrollar y dirigir estas labores, ya fuesen labradores, criadores de ganado o maestros de azúcar. La diversificación de los cultivos como medio de eliminar su limitación al azúcar, el tabaco y el café, proporcionaría además, según sus planes, la disminución en gran medida de la dependencia del mercado extranjero y el desarrollo del comercio interior. ${ }^{21}$

20 Puig-Samper Mulero, Miguel Angel: "Ramón de la Sagra....", págs. 61-80.

21 Sagra, Ramón de la: Memoria sobre la necesidad de ensanchar la esfera agrícola cubana, con nuevos cultivos de vegetales, así indígenas como exóticos. La Habana, Instituto Agronómico de La Habana, 1827. 
Por una real orden de 1829 se autorizó a la Intendencia de La Habana a establecer este tipo de escuela como centro de aclimatación y ensayo de nuevas especies con miras tanto a la utilidad que pudiera tener en España, como a la función divulgadora de los conocimientos científicos. Con el establecimiento de una "hacienda modelo" en el seno de la escuela se perseguían diferentes objetivos que confluían en un mismo fin: el crecimiento económico de Cuba mediante la transformación de sus estructuras económicas y sociales. Entre estos objetivos hay que indicar la diversificación y mecanización agrícolas como vías para el mejoramiento de las prácticas rurales, el logro de una autosubsistencia y la combinación de la agricultura y la ganadería en las pequeñas estancias. Para Ramón de la Sagra, la "hacienda modelo" que debía crearse tenía que poner en práctica los proyectos agrícolas trazados por él, a semejanza de las "haciendas modelos" europeas:

“... sería pues en mi opinión, la verdadera y única escuela de agricultura perfeccionada. En ella podía establecerse desde el principio el nuevo sistema agrícola que abraza el cultivo, la crianza de animales y el régimen económico de la contabilidad". ${ }^{22}$

A pesar de cierta oposición, las obras se iniciaron en los terrenos conocidos por los Molinos del Rey, en la falda de la loma del Príncipe de La Habana. Mientras, su director confeccionaba los documentos que regirían tanto la enseñanza como la actividad general de la hacienda. Una vez terminada la preparación de parte de los terrenos de la escuela comenzaron a ensayarse algunos cultivos, como el añil, cuya experimentación había sido puesta en marcha en el Jardín Botánico con anterioridad.

\section{Las "cartillas rústicas" como medio de enseñanza y práctica agrícola}

El cultivo y fabricación del añil en Cuba data de finales del siglo XVIII, cuando en 1797 el francés Gregorio Belaustre, con el apoyo de la Sociedad Patriótica, se dio a la tarea de establecer una añilería en Guanajay, sin grandes resultados. Posteriormente, en varias ocasiones fueron

22 Sagra, Ramón de la: Historia económica-política y estadística de la Isla de Cuba, o sea de sus verdaderos progresos en la población, la agricultura, el comercio y las rentas. La Habana, 1831, pág. 91. 
realizados intentos similares por el método de la fermentación que tampoco fructificaron. ${ }^{23}$

La utilidad de esta planta para las artes y la industria inclinó a Ramón de la Sagra a introducir en 1827 este cultivo en el Jardín Botánico, aplicando entonces un nuevo método de extracción del colorante. Este nuevo método, conocido como de la "hoja seca", ya había sido practicado en la colonia francesa de Senegal con buenos resultados y difería completamente del ensayado en Cuba con anterioridad. Las ventajas y desventajas de ambos métodos fueron valoradas por Sagra en los Anales de Ciencias, Agricultura, Comercio y Artes, así como su propia experiencia en los estudios comparativos que desarrolló tanto con las especies (indígena y de Guatemala) como con los procedimientos ya citados. ${ }^{24}$

Las muestras obtenidas despertaron interes en las autoridades coloniales por su excelente calidad y se adoptaron algunas medidas con vistas a su asimilación por parte de los agricultores, entre ellas la circulación de las instrucciones y el reparto de semillas de la especie de Guatemala. Sin duda la decisión del conde de Villanueva de enviar al gobierno español en 1829 algunas de estas muestras y la memoria escrita por Ramón de la Sagra, determinó que se autorizara oficialmente este cultivo en la isla. El profesor de química del Real Conservatorio de Artes de Madrid, José Luis Casaseca, a quien correspondió el análisis de estos resultados, expuso en sus conclusiones:

“... entre las muestras remitidas hay dos muy buenas que son el 3 y el 7 , siendo sobre todo el 3 de excelente calidad y superior al mejor de Guatemala del comercio de Madrid, lo que prueba, que habiendose conseguido en uno de los ensayos un añil excelente, que se obtendría siempre de buena calidad todo el que se fabrique, con tal que se cultive con el esmero debido la planta, y que se ejecuten con atención e inteligencia todas las operaciones de la extracción de la materia colorante". ${ }^{25}$

23 Sagra, Ramón de la: Memorias de la Institución Agrónoma de la Habana. La Habana, 1834, T. I, págs. 1-4.

24 Sagra, Ramón de la: "Memoria sobre el añil de Guatemala cultivado en el Jardín Botánico de La Habana", Anales de Ciencias, Agricultura, Comercio y Artes. La Habana, 1828, T. II, págs. 127-140.

25 Casaseca, José Luis: "Informe dado por el profesor de química aplicada a las artes D. José Luis Casaseca a la Real Junta del Museo de Ciencias Naturales de Madrid, sobre las muestras de añil fabricadas en La Habana", Memorias de la Institución Agrónoma de la Habana. La Habana, 1834, T. I, págs. 39-40. 
La observación de Casaseca de establecer la producción del añil en gran escala, por los beneficios que pudiera ofrecer en el mercado, permitió que en Junta Superior directiva de junio de 1831 fuese aprobada la creación del instituto; confirmado por real orden del 13 de septiembre del mismo año. ${ }^{26}$ Por otra parte, también se puso de manifiesto la importancia que para el desarrollo de estos estudios tenía la enseñanza de la química, asunto abordado en más de una ocasión por Sagra y reiterado en los planes de estudio de la institución. La introducción de nuevas experiencias de cultivos y procesos fabriles, incluída la del azúcar, propiciaron que el 6 de febrero de 1830 se expidiera una real cédula que disponía el establecimiento de una cátedra de química que, en realidad, no fue establecida hasta años más tarde, lo que impidió que los esfuerzos de Sagra y Casaseca se combinaran en este interesante proyecto. ${ }^{27}$

La primera experiencia en el cultivo del añil y extracción de su colorante en la recien establecida "hacienda modelo" arrojó los siguientes resultados, según el propio Sagra:

"He tenido la satisfacción de conseguir añiles de una calidad inmejorable, en panes como el de Bengala, y con tal regularidad en las operaciones, que creo exactamente confirmada la acepción que he tenido sobre el asunto, escrita en 1828, a saber, que consiguiendo la perfecta desecación de la hoja, era seguro el obtener añiles flor de primera especie por el sencillo método de la infusión de la hoja seca". ${ }^{28}$

Confirmada su tesis sobre la superioridad del procedimiento de la hoja seca por la calidad y por las ventajas económicas que representaba, fueron ampliados los terrenos destinados a este experimento. Un año después introducía Ramón de la Sagra en sus ensayos la semilla de especie de añil que se cultivaba en Senegal (indigófera emarginata) consiguiendo resultados aún superiores a los anteriores, tanto en calidad como en cantidad. Los progresos en su trabajo le motivaron a elaborar una "cartilla", como él mismo la denominó, que informaba en detalle tanto el proceso de cultivo como la extracción de la tintura. En principio esta me-

26 Sagra, Ramón de la: Memorias de la Institución.., T. I, pág. 2.

27 En el informe que el director del Jardín Botánico de La Habana, Ramón de la Sagra, ofreciera a la Sociedad Patriótica en 1828, fundamentaba la necesidad de los análisis químicos de las tierras y los abonos. Con posterioridad, en 1829, en el plan de enseñanza de la Institución Agrónoma explicaba la importancia de los estudios de la química para la formación de los labradores y maestros de azúcar. La real cédula citada expresaba el beneficio de esta discipilina para "la producción del ramo de azúcar y otras no menos interesantes".

28 Sagra, Ramón de la: Memorias de la Institución..,T. I, pág. 9. 
moria precisaba las especies de indigófera existentes en La Habana que pudieran ser indistintamente empleadas para este propósito. ${ }^{29}$

El primer capítulo, dirigido al cultivo, particularizaba en la preparación de terrenos, elección de semillas, siembra, cuidados de la planta y cosecha. Es importante apuntar que Ramón de la Sagra prestaba especial atención a la mejora de los terrenos por medio de los abonos naturales como el mantillo y los estiércoles de animales, así como en la aplicación de instrumentos "aratorios" que formaban parte de la colección adquirida por la institución como el arado de reja o vertedera, las rastras y el extirpador inglés de cinco rejas. ${ }^{30}$

La segunda parte conforma el proceso de extracción del colorante priorizando, entre los diversos métodos conocidos, el de la "hoja seca" en pequeños talleres construidos a muy bajo costo. Este capítulo está desarrollado en base a la experiencia adquirida por Sagra a partir de 1827 con este cultivo y a los estudios publicados por autores extranjeros, entre ellos los profesores franceses Plagne y Perrottet. ${ }^{31}$

El objetivo principal de esta cartilla no era otro que proporcionar orientación sobre la introducción de este nuevo cultivo que, dada su importancia, pudiera ser aplicada en grandes talleres. A este respecto Ramón de la Sagra comentó:

"Deseo simplemente que esta memoria sea útil, y lo más útil que posible sea, sin mirar en nada a mi reputación por haberla escrito, sino al bien que pueda producir". ${ }^{32}$

En 1833 se continuaron desarrollando los ensayos del añil en la Institución Agrónoma de La Habana, aunque con la llamada especie de Senegal, para lo cual se contaba con un taller y con una colección de instrumentos que sirvieran de modelo para la elaboración de una cartilla destinada a los instrumentos agrícolas. Cierto es que, a pesar de todo el esfuerzo desplegado por Sagra, las aspiraciones de extender este cultivo y de instalar una gran industria no llegaron a concretarse; no obstante es preciso señalar - como él mismo reconoció- que algunos propietarios

29 Ibídem, pág. 10.

30 Sagra, Ramón de la: "Del cultivo y fabricación del añil en la Isla de Cuba", Memorias de la Institución Agrónoma de la Habana, La Habana, 1834, T. III, págs. 77-87.

31 En los Anales de Ciencias, Agricultura, Comercio y Artes, 1827-1831, Ramón de la Sagra publicó las memorias de los profesores franceses citados y sus experiencias en el cultivo y fabricación del añil en la colonia de Senegal.

32 Sagra, Ramón de la: Memorias de la Institución.., T. III, pág. 76. 
de fincas estimulados con estos resultados introdujeron en sus tierras este cultivo. Entre ellos los corresponsales del Jardín habanero Diego Hernández Herrera y José Policarpio Columbié. ${ }^{33}$

Al igual que el añil progresaron otros cultivos en la Institución Agrónoma que también formaban parte del proyecto de diversificación que se había propuesto Ramón de la Sagra, y que también dieron lugar a la elaboración de cartillas y memorias, como medio de divulgar estas experiencias entre los colonos y hacendados. La publicación de los resultados de estos ensayos constituían la premisa fundamental para el éxito de la agricultura soñada por él. El resultado del estudio de la morera (morus multicaulis) para la crianza del gusano de seda, introducido por Ramón de la Sarga en 1832 en el Jardín Botánico de La Habana y la Institución Agrónoma, fue también objeto de demostración a través de la publicación de las memorias. ${ }^{34}$ Este estudio ofrecía no sólo las particularidades de un cultivo en Cuba sino también los beneficios económicos que en el mercado esta industria podría proporcionar. En esta oportunidad se pretendía un gran ensayo que ratificara los cálculos expresados en cuanto a costos y ganancias; por ello Ramón de la Sagra se dió a la tarea de ampliar los terrenos de cultivo para proveer a los hacendados y labradores interesados en su introducción.

No menos interesantes fueron los trabajos realizados acerca del cultivo del cacao. En 1828 ya contaba el Jardín habanero con un importante semillero para la distribución de semillas a los hacendados y colonos que las solicitasen. Para esta fecha también se contaba con una cartilla que orientaba sobre todo en lo concerniente al proceso de cultivo y elaboración del producto. En 1832, tras la real orden del 29 de agosto que disponía la protección de este cultivo en la isla, el conde de Villanueva solicitó a Ramón de la Sagra la reimpresión de estas instrucciones y dispuso que se repartieran de forma gratuíta a los interesados las semillas de cacao fresco. La memoria titulada "Cartilla para el cultivo del cacao en la Isla de Cuba" ofrecía importantes instrucciones sobre la clasificación botánica de la planta, tipo de terreno necesario para este cultivo, preparación de viveros, trasplantes, cosecha y, por último, los procedimientos para la elaboración del preciado alimento. ${ }^{35}$

33 Sagra, Ramón de la: "Del cultivo y fabricación del añil...", T. III, pág. 77.

34 Sagra, Ramón de la: "Sobre el cultivo de la morera y la crianza del gusano de seda en La Habana", Memorias de la Institución Agrónoma, La Habana, 1834, T. IV.

35 Sagra, Ramón de la: Cartilla para el cultivo del cacao en la lsla de Cuba, La Habana, 1834. 
Cabe subrayar que para promover estos cultivos Ramón de la Sagra conjugó armoniosamente la introducción de algunas reformas de instrumentos agrícolas tradicionales como la guataca, el machete y el arado. Asimismo, logró para la Institución Agrónoma la adquisición de modernos instrumentos en Estados Unidos y Francia; sin embargo, a pesar de su entusiasmo, los consideraba "muy distantes de la sencillez que entre nuestra gente del campo se requiere", por ello insistió en reiteradas oportunidades en la necesidad de formar un personal calificado capaz de utilizar la tecnología que deseaba aplicar.

La transformación técnica en la agricultura sólo era posible para nuestro pensador mediante el cambio del sistema de trabajo y la evolución de la esclavitud al trabajo asalariado. La "apatía salvaje" del negro esclavo, derivada del medio físico donde vivía antes de ser esclavizado y agravada por su condición de esclavo, le impedía trabajar en tareas que no fueran meramente manuales. La esclavitud, en su opinión, era "un sistema carente de estímulo y que elimina completamente la inteligencia del operario, para que predomine exclusivamente su fuerza muscular"; la introducción de una agricultura tecnificada era incompatible con la esclavitud ya que era "...imposible conseguir esmero, inteligencia y amor al trabajo de unos seres degradados, que un sistema absurdo hace considerar tanto más útiles cuando más estúpidos son". ${ }^{36}$ Para llevar a cabo dicha tecnificación Sagra proponía la introducción de colonos y trabajadores libres blancos y asiáticos, de acuerdo a los proyectos de colonización ideados en este período, ya comentados.

Ramón de la Sagra pretendió poner en marcha su "gran reforma" con la Institución Agrónoma, aunque, en su opinión, sólo constituyera un ligero ensayo. La introducción de cultivos y los ensayos fabriles muestran el gran esfuerzo de Ramón de la Sagra por reorganizar la actividad agrícola del país y consolidar la economía cubana. Pese a resultados no del todo favorables, Sagra continuó en su empeño tras su salida de $\mathrm{Cu}$ ba en 1835. Los innumerables trabajos realizados en los años posteriores evidencian el estado de atraso en que se hallaba la agricultura cubana. Ante ello Sagra insistía en aquellos aspectos que había preconizado durante su estancia en Cuba, pero ahora en correspondencia con los nuevos adelantos técnicos y las demandas del mercado europeo.

36 Sagra, Ramón de la: Cuba: $1860 \ldots . .$, págs. 33 y 198. 